\title{
Principios que rigen la responsabilidad internacional penal por crímenes internacionales*
}

\section{Principles that Define International Criminal Responsibility for International Crimes}

\section{Rosmerlin Estupiñan Silva**}

SUmario: I. Introducción. II. Problema jurídico y justificación. III. Aspectos metodológicos. IV. Presentación de resultados.V. Conclusiones. VI. Documentación. VII. Bibliografía.

* Artículo recibido el 7 de julio de 2011 y aprobado para publicación el 28 de septiembre de 2011.

Este artículo forma parte del Capítulo III de la investigación de tesis doctoral que lleva por título: "Los crímenes de guerra en Colombia. Estudio desde el derecho internacional y desde el derecho colombiano", defendida en julio de 2011 bajo la dirección del doctor Valentín Bou Franch.

** La autora es abogada colombiana, DEA en Derecho Internacional y Relaciones Internacionales de la Universidad de Valencia (España, 2008), Master 2 d'État en Droit Public spécialité Histoire, théorie et pratique des droits de l'homme de l'Universitè Pierre Mendes France (Francia, 2010) y, doctora en derecho (Departamento de Derecho Internacional "Adolfo Miaja de la Muela” de la Universidad de Valencia (España, 2011). Contactos: estupina@, alumni.uv.es. 
RESUMEN: La responsabilidad internacional penal de los individuos se inscribe en el marco de la lucha contra la impunidad de los crímenes más graves y tiene por objeto la persecución y sanción de los criminales que se encuentran a la cabeza de la empresa criminal. Por lo tanto, responde a una serie de principios generales de derecho penal y de derecho internacional que han sido sometidos a una evolución constante por parte de la jurisprudencia internacional. El artículo que se presenta a continuación muestra tal evolución y el estado actual de la discusión en el marco del Estatuto de Roma.

Palabras clave: derecho internacional penal, crímenes internacionales, responsabilidad internacional penal, principios.

ABSTRACT: Criminal responsibility in International Criminal Law forms part of the fight against impunity for international crimes by seeking the prosecution and punishment of the criminals who are at the head of the criminal enterprise. Therefore, said responsibility is guided by a number of general principles of Criminal Law and International Law that have evolved through international case law. The present herein shows the evolution and current status of this subject as part of the Rome Statute.

Descriptors: international criminal law, international crimes, international criminal responsibility, principles.

RÉSUMÉ: La responsabilité internationale pénale des individus s'inscrit dans le cadre de la lutte contre l'impunité des crimes les plus graves et a pour objet la poursuite et sanction des criminels qui se trouvent à la tête d'entreprises criminelles. Par conséquent, la responsabilité internationale pénale répond à toute une série de principes généraux de Droit pénal et de Droit international lesquels ont connu une évolution constante dans la jurisprudence internationale. Dans le cadre du Statut de Rome, l'article ci-dessous montre l'évolution et l'état actuel de la discusion.

Mots clés: droit international pénal, crimes internationaux, responsabilité internationale pénale, principes. 


\section{INTRODUCCIÓN}

La responsabilidad penal individual puede definirse como la obligación que tiene una persona natural de responder penalmente por sus actos, es decir, la imputación de una infracción penal a una persona determinada. ${ }^{1}$

El principio universalmente reconocido de "la responsabilidad del propio hecho" permite hacer que los individuos respondan de los hechos que les conciernen y que asuman las consecuencias penales de su comportamiento cuando éste contribuye de cualquier manera a la realización de un acto criminal. La responsabilidad penal concierne a las personas físicas de manera individual, pues incluso cuando se trata de infracciones perpetradas en grupo, cada persona debe responder de su propia contribución al acto criminal. ${ }^{2}$

La responsabilidad penal, así entendida, fue incorporada al derecho internacional a través de la jurisprudencia del Tribunal de Núremberg, después de la Segunda Guerra Mundial, fue reconocida por la Comisión de Derecho Internacional de las Naciones Unidas (en adelante: CDI) en la elaboración de los Principios de Núremberg y fue incorporada a los estatutos de los tribunales ad hoc y de la Corte Penal Internacional (en adelante: CPI).

La responsabilidad internacional penal, por la naturaleza de los crímenes que son atribuidos a la jurisdicción internacional penal, involucra la participación de multiplicidad de individuos dentro de la "macrocriminalidad" o "criminalidad de sistema" que impide la acción del Estado, bien por incapacidad de actuar o por connivencia con el crimen y sus autores.

En este sentido, la responsabilidad internacional penal por crímenes internacionales supone el cumplimiento de un número de condiciones previas, propias a la naturaleza de tales crímenes, que incluyen el umbral de gravedad (artículo 1o. del Estatuto de Roma) y la verificación de

1 Desportes, Frédéric y Le Gunehec, Francis, Droit pénal général, 15a. ed., París, Economica, 2008, p. 480, pár. 502.

2 Bouloc, Bernard, Droit pénal général, 21a. ed., París, Dalloz, 2009, p. 266, pár. 291. 
los elementos constitutivos de los crímenes (artículos 6-8 bis y 30 del Estatuto de Roma). ${ }^{3}$

El derecho penal clásico de los Estados consagra las formas de responsabilidad penal propias de crímenes y delitos cometidos a escala estatal: la autoría, la coautoría y la complicidad. No obstante, este derecho no está dirigido a discriminar la responsabilidad de los grandes criminales, que están a la cabeza de verdaderas empresas criminales pues, por regla general, no efectúa una valoración acuciosa del contexto de los crímenes.

Aunque la práctica internacional reciente es incierta en cuanto a lo que se considera un "alto responsable" encausado, ${ }^{4}$ la jurisprudencia de los tribunales ad hoc y la jurisprudencia de las Salas Preliminares de la CPI coinciden en el propósito de responder al desafío que impone un perfil de acusados de alto nivel y, en este sentido, incorporan y desarrollan una serie de principios que rigen la responsabilidad internacional penal del individuo.

3 Estatuto de la Corte Penal Internacional, Conferencia Diplomática de Plenipotenciarios de las Naciones Unidas sobre el establecimiento de una Corte Penal Internacional (17-71998) (en adelante: “Estatuto de Roma”).

4 Exceptuando las situaciones de Sudán y Libia (las causas contra sus presidentes y ministros del Interior respectivos), los asuntos que se encuentran bajo investigación de la CPI tienen que ver con conflictos regionales de menor extensión con respecto al territorio nacional donde tienen lugar, si bien, en el marco de crímenes internacionales cometidos a gran escala. En todos los casos los encausados son jefes de milicias o grupos rebeldes de talla mediana y pequeña. De hecho, las Decisiones de confirmación de cargos que han sido emitidas hasta 2011 se refieren, dos de ellas, a tres jefes de grupos rebeldes y milicias étnicas de la provincia de Ituri en la RDC: Thomas Lubanga Dylo (UPC: Union des patriotes congolais y su brazo armado: FPLC: Forces patriotiques pour la libération du Congo) Germán Katanga (RPI: Force de Résistance Patriotique en Ituri) y Mathieu Ngudjolo Chui (FNI: Front des Nationalistes et Intégrationnistes). La tercera confirmación de cargos corresponde a un jefe político, senador de la RDC actuando como jefe político-militar de una milicia que desplegó su acción al norte de la República Centroafricana: Jean-Pierre Bemba (MLC: Mouvement de libération du Congo): Véanse: CPI, Chambre préliminaire I (29 janvier 2007): Le Procureur c. Thomas Lubanga Dyilo, ICC-1/041/06-803, Décision sur la confirmation des charges (en adelante: “CPI, Affaire Lubanga, ICC01/04-01/06-803”), párs. 5-8; CPI, Pre-trial Chamber I (30 September 2008): The Prosecutor v. Germain Katanga and Mathieu Ngudjolo Chui, Case ICC-1/04-1/07-717, Decision on the confirmation of charges (en adelante: “CPI, Katanga case, ICC-01/04-01/07-717”), párs. 6-10; CPI, Chambre Préliminaire III (23 mai 2008): Le Procureur c. Jean-Pierre Bemba Gombo, ICC-01 / 04-01 / 08-1, Mandat d'arrêt à l'encontre de Jean-Pierre Bemba Gombo, pár. 9. 
El objeto de estudio: la responsabilidad internacional penal por crímenes internacionales pertenece a una categoría jurídica bien definida por el derecho internacional penal. ${ }^{5}$ En este marco, este artículo tiene como finalidad presentar una discusión abierta acerca de la aplicación de una serie de principios en materia de responsabilidad internacional penal, como base del proceso de imputación en los límites del Estatuto de Roma.

La creación reciente la CPI como jurisdicción internacional penal de carácter permanente no impide la pervivencia de crímenes internaciones que quedan fuera de su competencia, y esto se explica porque la responsabilidad de los Estados sigue siendo principal en su persecución y sanción (artículos 1o. y 17 del Estatuto de Roma).

La existencia de crímenes internacionales supone un compromiso estatal que no se limita a la obligación negativa de abstención en la perpetración de los crímenes. Los Estados tienen una obligación positiva de protección de la población civil y de persecución y sanción de los responsables de los crímenes internacionales, cuyo instrumento más acabado es el Estatuto de Roma. Al mismo tiempo, los Estados siguen teniendo una obligación positiva substancial de respeto de los derechos de los individuos encausados. ${ }^{6}$

La entrada en vigor del Estatuto de Roma en 2002 garantizó, sin embargo, que los crímenes más graves tengan una jurisdicción comple-

5 Esta investigación acoge la noción de derecho internacional penal desarrollada, entre otros, por el profesor sudre, quien lo define como una especialidad del derecho internacional, cuyo objeto es la represión del daño antijurídico causado a valores protegidos por el derecho internacional humanitario y derecho internacional de los derechos humanos y cuyo reconocimiento del individuo se limita a la atribución de la responsabilidad internacional penal, en su calidad de titular de obligaciones y no como titular de derechos. En este sentido, el derecho internacional penal no se ocupa de la protección internacional de derechos sino de la represión de atentados contra valores fundamentales de la humanidad que amenazan la paz y la seguridad colectiva. Véase Sudre, Frédéric, Droit européen et international des droits de l'homme, 8a. ed., París, Presses Universitaires de France, 2009, pp. 30-33.

6 CDI, doc. A/39/10* (27-7-1984): Informe de la Comisión de Derecho Internacional sobre la labor realizada en su 36 periodo de sesiones, 113, p. 13, pár. 40 . 
mentaria que puede ser convocada para garantizar la salvaguarda de los valores de la humanidad y ésta es la tarea de la CPI. Esta última posibilidad refuerza la importancia del estudio de los principios que rigen la responsabilidad internacional penal para una mejor adaptación de la jurisdicción nacional.

Este texto reflexiona sobre los principios que rigen la responsabilidad de los individuos por crímenes internacionales ante las jurisdicciones internacionales, tal como han sido desarrollados por la jurisprudencia y la doctrina desde Ia Primera Guerra Mundial y, en particular, por el Estatuto y la jurisprudencia del Tribunal de Núremberg, por los documentos de la CDI desde 1950 y por la jurisprudencia constante de los tribunales penales ad hoc y de la CPI, como será señalado en cada caso a lo largo del estudio. No obstante, la lista de principios aquí enunciados no tiene la pretensión de ser exhaustiva y, en la práctica, su aplicación desborda ampliamente el marco de los tribunales internacionales. Estos principios vienen siendo aplicados y han sido adaptados por los tribunales híbridos de Camboya y Sierra Leona, entre otros, así como en casos de crímenes internacionales juzgados por tribunales nacionales.

\section{ASPECTOS METODOLÓGICOS}

El método de conocimiento empleado es el "análisis-síntesis" de las fuentes de conocimiento e información. El método de redacción integra las herramientas del ensayo y la disertación jurídica.

La interpretación del Estatuto de Roma responde a las reglas de la interpretación de los tratados, consagradas en la Convención de Viena sobre el Derecho de los Tratados de 1969 en cuanto a la regla general de interpretación (artículo 31) y los medios de interpretación complementarios (artículo 32), en el marco de la jerarquía de las fuentes de Derecho Internacional consagradas por el Estatuto de la Corte Internacional de Justicia (en adelante CIJ) (artículo 38).

Adicionalmente, la pertinencia de las fuentes de interpretación del Estatuto de Roma radica, por una parte, en la autoridad del juez para hacer uso, de modo principal, de la letra del Estatuto de Roma (in- 
cluidas las claridades que aportan los trabajos preparatorios), de los Elementos de los Crímenes y de las Reglas de Procedimiento y Prueba. De manera complementaria, el juez ha venido haciendo uso los principios generales de derecho derivados de la jurisprudencia internacional y de la práctica de los Estados, tal como lo autoriza el artículo 21 del Estatuto de Roma.

Este estudio propone un abordaje transversal que está centrado en el periodo posterior a la entrada en vigor del Estatuto de Roma (2002), y hace referencia a la jurisprudencia internacional anterior cuyos principios generales han venido siendo incorporados dentro de la jurisprudencia de la CPI.

La documentación utilizada como fuente de información y conocimiento incluye convenios y otros instrumentos internacionales, documentos oficiales de los órganos de las Naciones Unidas y de la CPI. Los documentos oficiales son citados en su lengua original o en español como lengua oficial de cada institución, si está disponible.

La jurisprudencia internacional utilizada, en su versión oficial según la lengua de trabajo, pertenece en general a la CIJ, los tribunales ad hoc y a la CPI. El análisis señala de modo expreso la pertinencia de la jurisprudencia utilizada, así como su alcance y el contexto de su dictamen.

\section{PRESENTACiÓn DE REsultados}

\section{La responsabilidad internacional penal concierne a la persona natural individualmente considerada}

Después de la Primera Guerra Mundial, un órgano interestatal creado bajo el nombre de "Comisión sobre la responsabilidad de los autores de la guerra y la aplicación de sanciones” estableció los primeros criterios de responsabilidad internacional penal de los individuos basándose en los principios de derecho penal de la subjetividad y la individualización de la pena. Más tarde, los principios de responsabilidad internacional penal fueron desarrollados ampliamente por el Estatuto y la jurisprudencia del Tribunal de Núremberg y fueron retomados en 1950 por la CDI tras la creación del sistema de las Naciones Unidas: 
The question as to the subjects of criminal responsibility under the draft code was then examined by the Commission. The Commission decided that it would only deal with the criminal responsibility of individuals...

The Commission considered at some length the responsibility of a person acting as Head of State or as responsible government official. The tentative decision taken on this matter follows the relevant principle of the Nuremberg Charter and judgment as formulated by the Commission.

In respect of the responsibilitv of a person acting under superior orders, the Commission also decided tentatively to follow the relevant principle of the $\mathrm{Nu}$ remberg Charter and judgment, as formulated by the Commission. ${ }^{7}$

Los principios del Tribunal de Núremberg establecieron claramente la responsabilidad penal de cualquier individuo por crímenes internacionales: "Principio I. Toda persona que cometa un acto que constituya delito de derecho internacional es responsable de él y está sujeta a sanción". ${ }^{9}$

De esta manera, el primer principio de Núremberg corresponde al artículo 6-1 de su Estatuto, ${ }^{10}$ que establece la responsabilidad del Tribunal de sancionar "individuos", pues el establecimiento de la responsabilidad internacional penal supone la existencia de un deber de respeto del derecho internacional que sobrepasa la esfera de los Estados.

En armonía con esta premisa, la intermediación estatal en materia de responsabilidad desaparece frente a casos de crímenes internacionales particularmente graves, donde la sanción se retorna contra el individuo: "Crimes against international law are committed by men, not by abstract entities, and only by punishing individuals who commit such crimes can the provision of international law be enforced”. ${ }^{11}$

7 ILC, doc. A/CN.4/34 (29-7-1950): Report of the International Law Commission on the work of its Second Session, 385 pp. (en adelante: “Informe CDI 1950"), p. 380, párs. 151, 154 y 155.

8 NU, doc. A/RES/95(I) (11-12-1946): Confirmación de los principios de Derecho Internacional reconocidos por el estatuto del Tribunal de Núremberg, 1 p.

9 Informe CDI 1950, op. cit., p. 374, pár. 98.

10 Estatuto del Tribunal de Núremberg anexo al Acuerdo para el establecimiento de un Tribunal Militar Internacional encargado del juicio y castigo de los principales criminales de guerra del Eje europeo, Londres, 8 de agosto de 1945 (en adelante: Estatuto de Núremberg).

11 TMIN, Trial of the Major War Criminals before the International Military Tribunal, Núremberg, 1947, vol. I, p. 223. 
Por efecto de la importancia excepcional atribuida al respeto de las obligaciones en materia de derechos humanos y derecho internacional aplicable a los conflictos armados, el derecho internacional prevé una serie de consecuencias en caso de transgresión de la norma internacional por parte de los individuos. Estas consecuencias pueden llegar a ser de carácter internacional penal:

Nations can only act through human beings, and when Germany signed, ratified and promulgated The Hague and Geneva Conventions, she bound each one of her subjets to their observance. The defendants are in court not as members of a defeated nation but because they are charged with crime. ${ }^{12}$

En la jurisprudencia internacional, el Tribunal Penal Internacional para la Ex Yugoslavia (en adelante:TPIY) formuló el principio de la responsabilidad internacional penal de los individuos, identificando las dos nociones de este principio que enuncian, de una parte, que nadie puede ser tenido como responsable de un acto criminal perpetrado por otra persona y, de otra parte, que nadie puede ser declarado responsable de un crimen sin que haya sido declarado culpable de la infracción que se le imputa:

The basic assumption must be that in international law as much as in national systems, the foundation of criminal responsibility is the principle of personal culpability: nobody may be held criminally responsible for acts or transactions in which he has not personally engaged or in some other way participated (nulla poena sine culpa). ${ }^{13}$

El artículo 25-1 y 25-2 del Estatuto de Roma consagró sin margen de error la responsabilidad internacional penal de los individuos por los crímenes bajo competencia de la CPI:

12 TMIN, Trial of the Major War Criminals before the International Military Tribunal, Núremberg, 1948, vol. II, pp. 659 y 660. Citado por David, Eric, Principes de droit des conflits armés, 4a. ed., Bruselas, Bruylant, 2008, p. 590.

13 TPIY, Appeals Chamber (15 July 1999): The Prosecutor v. Dusko Tadic "Dule”, Case IT-941-A, Judgment (en adelante: “TPIY, Appeals Tadic, IT-94-1-A”), pár. 186. 
1. De conformidad con el presente Estatuto, la Corte tendrá competencia respecto de las personas naturales.

2. Quien cometa un crimen de la competencia de la Corte será responsable individualmente y podrá ser penado de conformidad con el presente Estatuto.

En el estado actual del Derecho Internacional Penal, la responsabilidad internacional penal es individual y personal.

En este sentido, es importante recordar que el artículo 9 del Estatuto de Núremberg dejó abierta la posibilidad de declarar la naturaleza criminal de un grupo u organización, y que el artículo 10, a su vez, determinó que la sola pertenencia a una organización declarada criminal podría constituir un crimen que, según la legislación de cada Estado Parte, era susceptible de la pena de muerte. ${ }^{14}$ De hecho, la jurisprudencia del Tribunal de Núremberg indicó la posibilidad de declarar la "criminalidad de grupo" y determinó como condición imprescindible para la declaración de tal carácter criminal el hecho de que la organización hubiera actuado como grupo en la perpetración de los crímenes:

... if satisfied of the criminal guilt of any organisation or group this Tribunal should not hesitate to declare it to be criminal because the theory of "group criminality" is new or because it might be unjustly applied by some subsequent tribunals... ${ }^{15}$

... The Secret Cabinet Council never met at all. A number of the cabinet members were undoubtedly involved in the conspiracy to make aggressive war; but they were involved as individuals, and there is no evidence that the cabinet as a group or organisation took any part in these crimes... ${ }^{16}$

No obstante, puede afirmarse que el establecimiento de la naturaleza criminal de las organizaciones tuvo más bien el efecto de una prueba de responsabilidad en la conspiración criminal para los individuos acusados, pertenecientes a las organizaciones que fueron declaradas

14 TMIN, Opinion and Judgment of the International Military Tribunal for the Trial of German Major War Criminals, Núremberg, 1946, p. I. Judgment, The Accused Organizations: General. 15 Idem.

16 Ibidem, The Reich Cabinet. 
criminales, ${ }^{17}$ pues, en todo caso, el Tribunal de Núremberg ratificó el carácter individual y personal de la responsabilidad internacional penal como uno de los principios generales de derecho más importantes:

In effect, therefore, a member of an organisation which the Tribunal has declared to be criminal may be subsequently convicted of the crime of membership and be punished for that crime by death...

Article 9, it should be noted, uses the words "The Tribunal may declare"... This discretion is a judicial one and does not permit arbitrary action, but should be exercised in accordance with well settled legal principles one of the most important of which is that criminal guilt is personal, and that mass punishments should be avoided...

A criminal organisation is analogous to a criminal conspiracy in that the essence of both is cooperation for criminal purposes... ${ }^{18}$

Aunque la declaración del carácter criminal de las organizaciones podría interpretarse como una excepción a la regla de la incriminación individual y personal, es importante señalar que, en todos los casos, la declaración relativa al carácter criminal de las organizaciones tuvo lugar en el marco de juicios adelantados contra individuos con acusaciones personales acerca de crímenes cometidos por éstos, conforme a las disposiciones del propio artículo 9 del Estatuto de Núremberg:

En el juicio de aquella persona o personas miembros de algún grupo u organización, el Tribunal podrá declarar (en relación con cualquier acto por el que dicha persona o personas puedan ser castigados) que el grupo u organización a la que pertenecía la citada persona o personas era una organización criminal (énfasis añadido).

De hecho, la condena de las organizaciones no se extendió a todos sus miembros, sino a un número determinado de cargos ocupados dentro

17 Conforme al Acta de cargos, fueron declaras criminales 4 de las organizaciones postuladas: el Partido Nazi, la Die Geheime Staatspolizei (Gestapo), la Die Sicherheitsdienst des Reichsfuehrer SS (SD), la Policía Secreta (SS). El Die Reichsregierung (Gabinete Ministerial), el Die Sturmabteilungen der Nationalsozialistischen Deutschen Arbeiterpartei (SA) y el Alto Estado Mayor Alemán, no fueron declaradas organizaciones criminales. Idem.

18 Ibidem, The Accused Organizations: General (énfasis añadido). 
de la estructura y, en una clara alusión a la responsabilidad individual, la condena fue proferida únicamente contra los miembros de esta organización que actuaron dolosamente, dirigiendo su voluntad y conciencia (mens rea) a la perpetración de crímenes internacionales. En una segunda alusión directa a la responsabilidad individual y personal, la condena excluyó a todos los miembros de la organización que entregaron sus cargos antes del comienzo de la guerra:

... The basis of this finding is the participation of the organisation in war crimes and crimes against humanity connected with the war, the group declared criminal cannot include therefore, persons who had ceased to hold the positions enumerated in the preceding paragraph prior to 1 st September, $1939 .{ }^{19}$

Since the declaration with respect to the organisations and groups will, as has been pointed out, fix the criminality of its members, that definition should exclude persons who had no knowledge of the criminal purposes or acts of the organisation and those who were drafted by the State for membership, unless they were personally implicated in the commission of acts declared criminal by Article 6 of the Charter as members of the organisation. Membership alone is not enough to come within the scope of these declarations. ${ }^{20}$

\section{La responsabilidad internacional penal no concierne a las personas} jurídicas aunque no excluye otras formas de responsabilidad internacional de los Estados

La responsabilidad penal de las personas jurídicas (personas morales) fue discutida y descartada durante los trabajos preparatorios del Estatuto de Roma. En contraste, en la última década, Estados como Francia y España incorporaron en su derecho interno la responsabilidad penal de las personas jurídicas como una ficción necesaria para la salvaguarda de los

19 TMIN, Opinion and Judgment of the International Military Tribunal for the Trial of German Major War Criminals, op. cit., Leadership corps Nazi Party, conclusion. En el mismo sentido: Ibidem, p. Gestapo and SD, conclusion, SS, conclusion.

20 Ibidem, The Accused Organizations: General. 
derechos de las víctimas (artículos 121-2 del Código Penal francés ${ }^{21}$ y 31 bis del Código Penal de España). ${ }^{22}$

Una prueba de la difícil evolución de la responsabilidad penal de las personas jurídicas en el plano internacional fue el rechazo de la propuesta de Francia, durante los trabajos preparatorios del Estatuto de Roma, sobre la posibilidad de vincular al Estado como tercero civil responsable en el marco de un proceso internacional penal. ${ }^{23}$

En este marco de diversidad de sistemas estatales, la Conferencia Diplomática del Estatuto de Roma aprobó el artículo 25-4, donde ratificó la responsabilidad internacional penal de los individuos, sin agotar los regímenes de responsabilidad internacional aplicables a los Estados: "4. Nada de lo dispuesto en el presente Estatuto respecto de la responsabilidad penal de las personas naturales afectará a la responsabilidad del Estado conforme al derecho internacional".

La fórmula adoptada por el artículo 25-4 del Estatuto de Roma dejó expresada la validez de la discusión sobre la responsabilidad internacional de los Estados que adelanta la CDI desde los años ochenta. ${ }^{24}$ De hecho, es preciso recordar que el Estado es responsable de las consecuencias del uso de la fuerza incluso cuando este uso se halla en conformidad con el derecho internacional de los conflictos armados ${ }^{25}$ y los crímenes internacionales son, a menudo, una de esas consecuencias ilícitas.

21 Loi 92-683 du 22 juillet 1992, portant réforme des dispositions générales du code pénal de la Republique de France, version consolidée au 7 janvier 2011. El texto íntegro en francés puede consultarse en el sitio oficial: http: / / www.legifrance.gouv.fr/affichCode.do?cidTexte =LEGI TEXT000006070719 (consultado: 18 de enero de 2011).

22 Ley Orgánica 10/1995, del 23 de noviembre, del Código Penal, Reino de España, BOE núm. 0281, del 24 de noviembre de 1995. No obstante, en todos los casos se excluye expresamente la responsabilidad penal de los Estados (artículos 31 -5 bis del Código Penal de España y 121-2 del Código Penal francés).

${ }^{23} \mathrm{NU}$, doc. A/CONF/183/C.1/WGGP/L.5 (19-6-1998): Working paper on article 23, paragraphs 5 and 6, 2 pp.

${ }^{24}$ Ambos, Kai, “Article 25: Individual criminal responsability”, en Triffterer, Otto (ed.), Commentary on the Rome Statute of the International Criminal Court, Observer's notes Article by Article, 2a. ed., Múnich, C. H. Beck, Hart, Nomos, 2008, pp. 743-770, p. 765. Para un estudio completo del estado actual de la discusión en materia de responsabilidad del Estado véase, entre otros: CDI, doc. A/56/10 (10-8-2001): Texto del proyecto de artículos sobre la responsabilidad del Estado por hechos internacionalmente ilícitos con sus comentarios, $591 \mathrm{pp}$.

25 David, Eric, op. cit., p. 71. 
No obstante, desde 1976, la CDI ha señalado que no es posible asimilar el derecho-deber reconocido a los Estados, que se refiere a la sanción de los individuos autores de crímenes internacionales bajo su competencia, con una forma especial de responsabilidad estatal de carácter penal. ${ }^{26}$

De la misma manera, la atribución de la responsabilidad internacional penal a los individuos pertenecientes a órganos del Estado no es asimilable a una responsabilidad internacional "penal" de los Estados. ${ }^{27}$

La necesidad de prevenir los crímenes internacionales justifica que un alto miembro de un órgano del Estado pueda ser tenido por responsable penal a título individual y que, al mismo tiempo, el Estado al que pertenece pueda quedar sometido a un régimen especial de responsabilidad internacional, sin que estas dos circunstancias sean de la misma naturaleza. ${ }^{28}$ Sólo cuando un Estado invoca la inmunidad para uno de sus órganos y pide a una jurisdicción extranjera no perseguir penalmente al funcionario cuestionado, el Estado concernido asume la responsabilidad por todo acto internacionalmente ilícito cometido por sus órganos en el marco de la protección invocada, ${ }^{29}$ pero aun en esta hipótesis, la responsabilidad del Estado no adquiere una naturaleza penal:

La responsabilidad internacional de los Estados se genera en forma inmediata con el ilícito internacional atribuido al Estado y, para establecer que se ha producido una violación de los derechos consagrados en la misma, no se requiere determinar, como ocurre en el derecho penal interno, la culpabilidad de sus autores o su intencionalidad y tampoco es preciso identificar individualmente a los agentes a los cuales se atribuyen los hechos violatorios. Es en ese marco que la Corte efectúa la determinación de responsabilidad internacional del Estado en este caso, la que no corresponde condicionar a estructuras propias y específicas del derecho penal, interno o internacional, definitorias de criterios de imputabilidad o responsabilidades penales individuales; tampoco es necesario definir los ámbitos de

26 CDI, doc. A/31/10* (23 de julio de 1976): Informe de la Comisión de Derecho Internacional sobre la labor realizada en su 28o. período de sesiones, p. 102, pár. 21 como comentario al artículo 19.

27 Ibidem, pár. 21, nota 473.

28 Idem.

29 CIJ, Certaines questions concernant l'entraide judiciaire en matière pénale (Djibouti c. France), Arrêt du 4 juin 2008, CIJ Recueil 2008, p. 177, pár. 196. 
competencia y jerarquía o subordinación de cada agente estatal involucrado en los hechos. ${ }^{30}$

Otro elemento que merece una reflexión en el marco de los crímenes internacionales es la distinción entre la responsabilidad internacional penal y la obligación de reparación del Estado. La obligación de reparación y la responsabilidad de los Estados por los hechos de sus órganos durante los conflictos armados internacionales fueron enunciadas de modo general en el artículo 3 de la Convención H. IV de 1907: "La Parte beligerante que viole las disposiciones de dicho Reglamento estará obligada a indemnización, si fuere el caso, y será responsable de todos los actos cometidos por las personas que hagan parte de su fuerza armada”.

El artículo 91 del Protocolo I adicional a los Convenios de Ginebra de 1949 consagra una disposición similar sobre la responsabilidad de los Estados: "La Parte en conflicto que violare las disposiciones de los Convenios o del presente Protocolo estará obligada a indemnizar si hubiere lugar a ello. Será responsable de todos los actos cometidos por las personas que formen parte de sus fuerzas armadas".

En igual sentido, el artículo 75-6 del Estatuto de Roma preservó los derechos de las víctimas a obtener una reparación por el daño causado y la jurisprudencia de la CPI podría verse inclinada a estudiar una actuación judicial internacional de reparación contra el Estado, posterior a la sentencia, en particular cuando los condenados sean miembros de órganos del Estado o hayan actuado como órganos de facto: "Nada de lo dispuesto en el presente artículo podrá interpretarse en perjuicio de los derechos de las víctimas con arreglo al derecho interno o el derecho internacional".

Esta acción podría ser emprendida oficiosamente, como acción de repetición del Fondo Fiduciario de la CPI (artículo 79 del Estatuto de Roma) contra el Estado concernido, o a petición de las víctimas participantes en el proceso y como consecuencia de la expresión de sus opiniones y preocupaciones (artículo 68-3 del Estatuto de Roma),

30 Corte IDH, Caso La Cantuta v. Perú, Sentencia de Fondo, Reparaciones y Costas del 29 de noviembre de 2006, Serie C-162, pár. 156. 
teniendo en cuenta que el artículo 21-1 del Estatuto de Roma faculta a la CPI para aplicar:

b) En segundo lugar, cuando proceda, los tratados aplicables, los principios y normas del derecho internacional, incluidos los principios establecidos del derecho internacional de los conflictos armados.

c) En su defecto, los principios generales del derecho que derive la Corte del derecho interno de los sistemas jurídicos del mundo, incluido, cuando proceda, el derecho interno de los Estados que normalmente ejercerían jurisdicción sobre el crimen, siempre que esos principios no sean incompatibles con el presente Estatuto ni con el derecho internacional ni las normas y estándares internacionalmente reconocidos.

\section{La responsabilidad internacional penal se basa en el principio} de legalidad de los delitos y las penas

El principio de legalidad en la ley penal o del imperio de la ley es un principio fundamental de derecho penal según el cual todo ejercicio del poder punitivo debe estar sometido a la voluntad de la ley. ${ }^{31}$

El Derecho Internacional Penal estuvo regido hasta finales del siglo $\mathrm{XX}$ por el principio de sustantive justice, que privilegia el interés general sobre el interés del individuo y, en consecuencia, subordina la aplicación del principio de legalidad a la justicia efectiva. ${ }^{32}$ La tradición del respeto de la soberanía de los Estados y del ejercicio punitivo como máxima demostración de la soberanía impidió la configuración de infracciones, penas y procedimientos penales en el orden internacional hasta bien entrado el siglo XX.

31 Las tesis defendidas por Cesar Beccaria en el siglo XVIII en Los delitos y las penas (1764) sirvieron como base al jurista alemán von Feuerbach, quien acuñó la máxima: nullum crimen, nulla poena sine proevia lege, es decir, que para que una conducta sea calificada como una infracción hace falta que ésta haya sido descrita como tal con anterioridad a la ejecución de la conducta y, de la misma manera, la pena a imponer debe haber sido previamente especificada por la ley. Véase, por ejemplo: Zugaldía Espinar, José Miguel (dir.), Fundamentos de derecho penal. Parte general, 4a. ed., Valencia, Tirant lo Blanch, 2010, p. 73.

32 Cassese, Antonio, International Criminal Law, 2a. ed., Nueva York, Oxford University Press, 2008, pp. 140-143. 
En consecuencia, durante los episodios de graves violaciones a los derechos humanos y al derecho internacional de los conflictos armados, la comunidad internacional hizo uso de la costumbre internacional y de los principios generales de derecho internacional para justificar su ejercicio punible ex post facto y llegó incluso a cuestionar la aplicabilidad del principio de legalidad en materia internacional penal. En la práctica, sólo los crímenes de guerra encontraron una base consuetudinaria y convencional sólida para la aplicación del principio de legalidad por parte de los tribunales internacionales establecidos a partir de 1945.

A finales del siglo XX, los tribunales ad hoc acogieron implícitamente el respeto al principio de legalidad penal como principio general de derecho internacional. Para ello, la jurisprudencia hizo uso de otros principios generales de derecho internacional e incorporó el acumulado convencional en materia de respeto al derecho internacional de los derechos humanos y al derecho internacional de los conflictos armados. Esta referencia contribuyó a dar claridad y precisión a los elementos de los crímenes internacionales. ${ }^{33}$

En este sentido, cabe recordar que el principio de legalidad en la ley penal ha sido consagrado en numerosos instrumentos internacionales, en particular, en el artículo 11-2 de la Declaración Universal de los Derechos Humanos de 1948, que dispone: "Nadie será condenado por actos $\mathrm{u}$ omisiones que en el momento de cometerse no fueron delictivos según el Derecho nacional o internacional. Tampoco se impondrá pena más grave que la aplicable en el momento de la comisión del delito".

El espíritu de esta disposición ha sido retomado en los artículos 2-5 y 7 de la Convención Europea de los Derechos Humanos de 1950, en el artículo 15 del Pacto Internacional relativo a los Derechos Civiles y Políticos de 1966 y en el artículo 9 del Pacto de San José, ${ }^{34}$ entre otros.

En cuanto al Derecho Internacional Penal en vigor, éste ha consagrado explícitamente la existencia y la actualidad del principio de legalidad

33 Ibidem, p. 145; TPIY, Chambre d'Appel (2 octobre 1995): Le Procureur c. Dusko Tadic alias Dule, Affaire IT-94-1, Arrêt relatif à l'appel de la Défense concernant l'exception préjudicielle d'incompétence, párs. 140 y 141.

34 Convención Americana sobre Derechos Humanos, suscrita en la Conferencia Especializada Interamericana sobre Derechos Humanos de San José de Costa Rica (en adelante Pacto de San José), 22 de noviembre de 1969. 
de la ley penal y al mismo tiempo ha dotado de un contenido particular los cuatro presupuestos del principio de legalidad. De hecho, los trabajos preparatorios del Estatuto de Roma dejaron algunos elementos de interpretación al respecto:

Con respecto a la especificación de los crímenes, se expresó la opinión de que un instrumento de procedimiento en que se enumeraran los crímenes en lugar de definirlos no satisfaría los requisitos del principio de legalidad (nullum crimen sine lege y nulla poena sine lege) y que los elementos constitutivos de cada crimen deberían especificarse para evitar toda ambigüedad y garantizar el respeto pleno de los derechos de los acusados...

A juicio de varias delegaciones, sería importante consignar en el Estatuto el principio de la no retroactividad de sus disposiciones. Se dijo también que había que incluir una disposición por la cual la Corte no pudiera imponer una sanción sobre la base del derecho consuetudinario si el Estatuto no consignaba una definición clara del crimen. ${ }^{35}$

En el asunto Tadic, que constituye piedra angular de la jurisprudencia de los tribunales ad hoc, quedó establecido que la no retroactividad de la norma internacional penal y su vigencia anterior a los hechos que se juzgan (lex proevia) debe ser interpretada teniendo en cuenta otras fuentes de derecho internacional. En efecto, las acusaciones de crímenes contra la humanidad (tratamientos inhumanos, transferencia ilegal y desapariciones forzadas, entre otras), así como de crímenes de guerra en el marco de los ataques a Bosnia Herzegovina (provincia de Prijedor), se enfrentaron a la discusión de la legalidad del Estatuto del TPIY creado ex post facto:

What this principle requires is that a person may only be found guilty of a crime in respect of acts which constituted a violation of the law at the time of their commission...

That principle does not prevent a court, either at the national or international level, from determining an issue through a process of interpretation and clarifi-

35 NU, doc. A/50/22 Suplemento 22 (6-9-1995): Informe del Comité Especial sobre el establecimiento de una Corte Penal Internacional, 66 pp., párs. 57 y 58. 
cation as to the elements of a particular crime; nor does it prevent a court from relying on previous decisions which reflect an interpretation as to the meaning to be ascribed to particular ingredients of a crime. ${ }^{36}$

En este sentido, la noción de "norma" se refiere en primer lugar a un instrumento internacional suscrito con las formalidades del derecho de los tratados, cuya expresión más acabada es el Estatuto de Roma (artículo 22-1 del Estatuto de Roma). No obstante, el juez internacional goza de un amplio margen para dinamizar la ley formal haciendo uso de las fuentes de derecho internacional, en particular, los principios generales de derecho internacional y la costumbre internacional, con el fin de adaptase a los cambios en las condiciones sociales internacionales y responder al objetivo máximo de administrar justicia (artículo $21 \mathrm{del}$ Estatuto de Roma). ${ }^{37}$

Por lo tanto, la especificidad de la ley internacional penal en materia de infracciones (artículo 22-1-a del Estatuto de Roma), penas (artículo 23 del Estatuto de Roma) y procedimiento (artículo 51-4 del Estatuto de Roma), no excluye el uso de principios generales de derecho internacional y de derecho consuetudinario como fuente complementaria (artículo 21-1-b del Estatuto de Roma) como es de uso general en la práctica jurisprudencial internacional. ${ }^{38}$

En efecto, la garantía de una interpretación estricta de la norma internacional penal (lex certa) que excluye la analogía fue consagrada en el artículo 22-2 del Estatuto de Roma. ${ }^{39}$ En consecuencia, el texto del tratado es, en sí mismo, el centro de toda interpretación posible. No obstante, las interpretaciones alusivas al documento anexo de los Elementos de los Crímenes y de las Reglas de Procedimiento y Prueba están expresamente permitidas por el artículo 31 de la Convención de

36 TPIY, Appeals Chamber (24 March 2000): The Prosecutor v. Zlatko Aleksovski, Case IT95-14-A, Judgment, párs. 126 y 127. Véase la interpretación extensiva del principio de no retroactividad sobre los crímenes de guerra en los conflictos armados internos en: TPIY, Appeals Tadic, IT-94-1-A, op. cit., nota 12, párs. 94-137.

37 Ibidem, párs. 97.

38 TPIY, Trial Chamber II (10 December 1998): The Prosecutor v. Anto Furundzija, Case IT95-17/1-T, Judgment (en adelante: “TPIY, Trial Furundzija, IT-95-17/1-T”), pár. 177.

39 Werle, Gerhard, Principles of the International criminal law, 2a. ed., La Haya, TMC Asser Press, 2009, p. 974. 
Viena sobre el Derecho de los Tratados de 1969, y han sido autorizadas por el artículo 21 del Estatuto de Roma.

4. Los responsables por crímenes internacionales no son sujetos calificados

En 1998 la jurisprudencia del Tribunal Penal Internacional para Ruanda (en adelante: TPIR) afirmó que el objetivo último del derecho internacional aplicable a los conflictos armados y del derecho internacional de los derechos humanos: la protección de las víctimas, exige una interpretación menos restrictiva de las personas susceptibles de cometer los crímenes internacionales. En la ocurrencia, Jean-Paul Akayesu, alcalde y profesor, primera autoridad civil de la comuna de Taba en Ruanda, fue acusado de genocidio y crímenes de guerra a pesar de su condición de persona civil:

Due to the overall protective and humanitarian purpose of these international legal instruments, however, the delimitation of this category of persons bound by the provisions in Common Article 3 and Additional Protocol II should not be too restricted... The objective of this approach, thus, would be to apply the provisions of the Statute in a fashion which corresponds best with the underlying protective purpose of the Conventions and the Protocols. ${ }^{40}$

La inexistencia de indicación precisa en cuanto a la exigencia de un sujeto calificado como autor de los crímenes fue subrayada por el TPIR, quien afirmó que una persona civil, en virtud de su autoridad en los asuntos públicos, podía sostener la guerra o contribuir a un ataque generalizado y sistemático contra la población, con la misma eficiencia que un comandante militar, y que por lo tanto las personas civiles eran susceptibles de cometer crímenes internacionales:

... La Chambre d'appel considère que la protection minimum des victimes énoncée à l'article 3 commun implique nécessairement la sanction effective des au-

40 TPIR, Trial Chamber I (2 September 1998): The Prosecutor v. Jean-Paul Akayesu, Case ICTR-96-4-T, Judgment, pár. 631. 
teurs de violations de celui-ci. Or, cette sanction doit être applicable à toute personne sans distinction, comme le commandent les principes de la responsabilité pénale individuelle établis notamment par le Tribunal de Nuremberg. La Chambre d'appel est donc d'avis que le droit international humanitaire serait déprécié et remis en cause si l'on admettait que certaines personnes puissent être exonérées de la responsabilité pénale individuelle pour violation de l'article 3 commun sous prétexte qu'elles n'appartiendraient pas à une catégorie particulière. ${ }^{41}$

ElTPIR estimó que la existencia de un nexo entre el conflicto armado y los crímenes cometidos, para el caso de los crímenes de guerra, así como la existencia de un plan o política, para el caso de los crímenes de lesa humanidad, implican, en sí mismos, la adhesión o pertenencia del autor del crimen a una estructura (Estado u organización) y, por lo tanto, dicha condición de pertenencia no es un requisito previo sino un hecho constatado que deriva del crimen:

... l'article 3 commun requiert un lien étroit entre les violations commises et le conflit armé. Ce lien entre les violations et le conflit armé implique que, dans la plupart des cas, l'auteur du crime entretiendra probablement un rapport particulier avec une partie au conflit. Il n'en reste pas moins que ce rapport particulier n'est pas un préalable à l'application de l'article 3 commun... ${ }^{42}$

ElTPIR adoptó esta tesis como jurisprudencia internacional consolidada hasta el siglo XX en el asunto contra Alfred Musema, director de la fábrica de té de la provincia de Gisovo por actos de genocidio. ${ }^{43}$

Por su parte, la jurisprudencia de la CPI ha venido consolidando la misma posición, como se desprende de la Decisión de confirmación de cargos contra el ex senador de la República Democrática del Congo, Jean-Pierre Bemba Gombo, por crímenes de guerra y crímenes de lesa humanidad. ${ }^{44}$ En este caso, Bemba Gombo deberá responder por su respon-

41 TPIR, Chambre d'Appel (1 juin 2001): Le Procureur c. Jean-Paul Akayesu, ICTR-96-4-A, Arrêt, pár. 443.

42 Ibidem, párs. 424-445.

43 TPIR, Trial Chamber I (27 January 2000): The Prosecutor v. Alfred Musema-Uwimana, Case ICTR-96-13-T, Judgment and Sentence, párs. 268, 274-275.

${ }_{44}$ CPI, Pre-trial Chamber II (15 June 2009): The Prosecutor v. Jean-Pierre Bemba Gombo, ICC1/05-1/08-424, Decision Pursuant to Article 61(7)(a) and (b) of the Rome Statute on the 
sabilidad como superior civil de tropas acusadas de crímenes cometidos en territorio de la República Centroafricana. En el mismo sentido, la jurisprudencia de la CPI en los asuntos Lubanga y Katanga - Ngudjolo Chui ha venido haciendo una interpretación amplia del término "nacionales" para referirse a los ejércitos comprometidos en algunos actos constitutivos de crímenes de guerra, como el reclutamiento y alistamiento de menores de 15 años. ${ }^{45}$

\section{La responsabilidad internacional penal prevalece sobre el derecho interno}

La responsabilidad internacional penal de los individuos no depende de la existencia de normas penales de derecho interno que proscriban las conductas encausadas: "Principio II. El hecho de que el derecho interno no imponga pena alguna por un acto que constituya delito de derecho internacional no exime de responsabilidad en derecho internacional a quien lo haya cometido". ${ }^{46}$

La responsabilidad internacional penal del individuo puede ser reclamada ante una jurisdicción internacional penal, con independencia de que la conducta alegada se encuentre sancionada, o no, en la legislación interna del Estado concernido. Ésta es una consecuencia de la supremacía del derecho internacional penal sobre el derecho penal de los Estados y es una constatación de que los individuos tienen responsabilidades que trascienden sus obligaciones nacionales. ${ }^{47}$

El Preámbulo del Estatuto de Roma establece la lista de motivos que justifican la superioridad de la norma internacional penal y su vocación complementaria del derecho interno de los Estados. En primer lugar, se refiere al reconocimiento de una serie de valores protegidos por la comunidad internacional: la paz, la seguridad y el bienestar, este último referido no sólo a las garantías mínimas de existencia sino a la protección del medio ambiente a la que se refieren expresamente los crímenes de guerra en los conflictos armados internacionales (artículo 8-2-b-iv

\footnotetext{
Charges of the Prosecutor Against Jean-Pierre Bemba Gombo.

45 CPI, Affaire Lubanga, ICC-01/04-01/06-803, op. cit., párs. 284 y 285.

46 Informe CDI, 1950, op. cit., p. 374, pár. 100.

47 Ibidem, p. 375, pár. 102.
} 
del Estatuto de Roma), o incluso, a una noción más amplia de la dignidad humana (v. gr. art. 7-1-k, artículos 8-2-b-xxi y 8-2-c-i del Estatuto de Roma).

En segundo lugar, la supremacía está justificada por el objeto de la norma internacional penal: "los más graves crímenes [que] constituyen una amenaza para la paz, la seguridad y el bienestar de la humanidad" (Preámbulo del Estatuto de Roma). La delimitación del objeto del derecho internacional penal ratione materiae a los crímenes internacionales más graves y no a todos los crímenes internacionales supone, por un lado, la intervención del jus puniendi internacional como ultima ratio y, por otro lado, la cooperación de los Estados para asegurar la acción efectiva de la justicia. ${ }^{48}$

Nótese que la cooperación estatal y la adopción de normas nacionales en materia de crímenes internacionales de competencia de la CPI han sido formuladas como deberes de los Estados. Tal formulación y el hecho de que el contenido normativo del Estatuto de Roma sea una obligación convencional exigible, autorizan la interpretación de la supremacía del derecho internacional penal en vigor sobre la ley interna de los Estados.

El artículo 13-b del Estatuto de Roma, en virtud del cual el Consejo de Seguridad de las Naciones Unidas puede remitir "al Fiscal una situación en que parezca haberse cometido uno o varios de esos crímenes", es una demostración adicional de la autoridad superior del Derecho Internacional Penal frente a los crímenes internacionales más graves de competencia de la CPI. ${ }^{49}$ En este sentido, aun en los casos en que el Estado no se encuentra vinculado a las obligaciones convencionales del Estatuto de Roma (las situaciones de Sudán y Libia) sigue vinculado por las obligaciones internacionales derivadas del tratado constitutivo (la Carta) de Naciones Unidas y por los principios generales de derecho

48 Bergsmo, Morten y Triffterer, Otto, "Preamble", en Triffterer, Otto (ed.), Commentary on the Rome Statute of the International Criminal Court, Observer's notes Article by Article, 2a. ed., München, C. H. Beck, Hart, Nomos, 2008, pp. 1-14, p. 9.

49 Willams, Sharon. A. y Schabas, William A., “Article 13: Exercise of Jurisdiction”, en Triffterer, O. (ed.), Commentary on the Rome Statute of the International Criminal Court, Observer's notes Article by Article, 2a. ed., Múnich, C. H. Beck, Hart, Nomos, 2008, pp. 570. 
internacional aplicables en caso de violaciones graves a los derechos humanos y al derecho internacional de los conflictos armados.

\section{Las inmunidades diplomáticas no son un eximente de la responsabilidad internacional penal}

La aplicación de la responsabilidad internacional penal ha autorizado una excepción al principio de derecho internacional de la inmunidad de jurisdicción penal de los altos funcionarios que ejercen la representación internacional de los Estados.

La inmunidad de jurisdicción penal y la responsabilidad internacional penal son abordadas por el derecho internacional como conceptos de naturaleza distinta, es decir, la inmunidad de jurisdicción reviste un carácter procesal, mientras que la responsabilidad penal se refiere al derecho sustantivo. De tal manera que la inmunidad de jurisdicción puede obstaculizar la persecución penal durante un cierto tiempo, pero no exonera al individuo de su responsabilidad penal: "Principio III. El hecho de que la persona que haya cometido un acto que constituya delito de derecho internacional haya actuado como Jefe de Estado o como autoridad del Estado, no la exime de responsabilidad conforme al derecho internacional". ${ }^{50}$

En derecho internacional existe una serie de inmunidades que tienen por objeto la protección de cierta categoría de personas frente a la acción internacional. El primer grupo corresponde a las inmunidades funcionales (functional immunities, ratione materiae $\mathrm{u}$ organic immunities). Conforme a este tipo de inmunidades, todos los agentes (de jure o de facto) del Estado que actúen en ejercicio de su mandato oficial se encuentran protegidos por el principio de soberanía estatal y no responden por sus actos ante la jurisdicción de otro Estado. Conforme a la costumbre internacional, sólo el Estado es responsable por las presuntas violaciones al derecho internacional que el agente del órgano estatal haya cometido. La inmunidad funcional tiene algunas características de especial relevancia para el derecho internacional penal: (1) constituye una defensa

50 Informe CDI 1950, op. cit., p. 375, pár. 103. 
de derecho sustantivo oponible por el individuo, si bien, al Estado reviene la responsabilidad internacional; (2) tiene aplicación funcional, es decir, circunscrita a la naturaleza del mandato estatal; (3) no cesa con el fin del mandato del agente del Estado, es decir, los actos cometidos por el agente estatal durante el periodo de su mandato siguen cubiertos por la inmunidad funcional y sólo el Estado que otorga la inmunidad puede asumir la competencia de las investigaciones respectivas, y (4) puede ser invocada erga omnes, es decir, es oponible ante cualquier Estado, quien tiene la obligación internacional de respetarla.

El segundo grupo de inmunidades se basa en la costumbre internacional y en un conjunto de tratados que otorgan inmunidades personales (personal immunities o ratione personae) a cierta categoría de individuos en razón de sus funciones. Las inmunidades personales abarcan la vida pública y privada de estas personas que ocupan los más altos cargos del Poder Ejecutivo, en particular, como agentes de la política exterior del Estado: el jefe de Estado, los altos funcionarios de la diplomacia y la política exterior y los más altos representantes del Estado en las organizaciones internacionales.

La inmunidad personal: (1) constituye una defensa procesal para el oficial del Estado que le hace inmune ante cualquier jurisdicción con independencia de su responsabilidad conforme al derecho sustantivo; (2) es de carácter global, es decir, abarca todas las conductas públicas y privadas del oficial del Estado más allá del ejercicio de sus funciones; (3) protege una categoría específica de agentes del Estado que ejercen las más altas funciones de representación internacional: los jefes de Estado, los jefes de gobierno y los ministros de relaciones exteriores; (4) termina con el fin del mandato de representación estatal, y (5) no puede ser invocada erga omnes, sino con respecto a los Estados en cuyo territorio el oficial concernido debe pasar (derecho de paso o jus transitus innoxii).

Un tercer grupo de inmunidades que suele ser mencionado corresponde a las inmunidades nacionales otorgadas, en virtud de las leyes internas de un Estado, a los más altos funcionarios de los poderes públicos, en particular: el jefe de Estado, los miembros del gabinete y los miembros del parlamento. Este tipo de inmunidades se encuentra regido por el derecho interno de los Estados y no reviste mayor interés para el derecho internacional penal. 
Las inmunidades diplomáticas (personal y funcional), que fueron largo tiempo utilizadas como garantía de impunidad, han sido progresivamente limitadas por el Derecho Internacional Penal: "He who violates the laws of war cannot obtain immunity while acting in pursuance of the authority of the State if the State in authorizing action moves outside its competence under international law". ${ }^{5}$

La jurisprudencia constante de la CIJ permite afirmar que las inmunidades diplomáticas no pueden ser confundidas con la impunidad en materia de crímenes internacionales por múltiples razones.

En el asunto Djibouti contra Francia, la CIJ estimó que un jefe de Estado o un ministro de Asuntos Exteriores pueden ser convocados a rendir testimonio ante autoridades de terceros países (Francia, en el caso preciso) en cuestiones penales, siempre que estas solicitudes no tengan carácter obligatorio, sin que con ello se esté atentando contra sus inmunidades diplomáticas. ${ }^{52}$ Cabe señalar que ninguna inmunidad personal puede ser alegada por otros altos funcionarios del Estado que cumplen funciones no relacionadas con la representación internacional. ${ }^{53}$

Los funcionarios que gozan de inmunidades diplomáticas por parte de un Estado, no se benefician de ninguna inmunidad de derecho internacional en su propio país y, a excepción de las inmunidades de derecho nacional atribuidas a su función, pueden ser procesados por las jurisdicciones nacionales competentes, conforme a las reglas de derecho interno en vigor en cada caso.

La inmunidad diplomática cesa de existir en derecho internacional por voluntad del Estado que la otorga, con lo cual, un Estado puede suprimir este privilegio cuando uno de sus funcionarios resulta implicado en la comisión de graves crímenes.

En proferida contra Senegal por Bélgica, a raíz del rechazo de la extradición del ex presidente de Chad Hissen Abrè, acusado de crímenes contra la humanidad por el juez belga, la CIJ estimó que, en el caso de la inmunidad personal, cuando la persona deja de ocupar el cargo confor-

51 TMIN, Trial of the Major War Criminals before the International Military Tribunal, Núremberg, 1947, vol. I, p. 223.

52 CIJ, Certaines questions concernant l'entraide judiciaire en matière pénale (Djibouti c. France), Arrêt du 4 juin 2008, CIJ Recueil 2008, p. 177, párs. 170 y 171.

53 Ibidem, pár. 194. 
me al cual se benefició de ésta, pierde todos sus beneficios y cualquier tribunal de un tercer Estado, a condición de ser competente en derecho internacional, puede llamar a juicio al ex funcionario, por hechos ocurridos antes o después del ejercicio de su función, así como por actos cometidos durante el periodo de funciones a título privado. ${ }^{54}$

Finalmente, un funcionario que se beneficia o que se ha beneficiado de la inmunidad diplomática puede ser perseguido penalmente ante las jurisdicciones penales internacionales. De hecho, la CPI, al igual que el TPIY y el TPIR en el marco de su competencia, prevé expresamente la excepción de inmunidad en su artículo 27-2: "Las inmunidades y las normas de procedimiento especiales que conlleve el cargo oficial de una persona, con arreglo al derecho interno o al derecho internacional, no obstarán para que la Corte ejerza su competencia sobre ella”.

La jurisprudencia internacional penal ha venido constatando la ausencia de inmunidad en materia de responsabilidad internacional penal que se ha visto confirmada en las sucesivas órdenes de detención contra Omar Al Bashir, presidente en ejercicio del Estado de Sudán, por crímenes internacionales, incluidos los crímenes de guerra consistentes en ataque a la población civil y saqueo (artículos 8-2-e-i y 8-2-e-v del Estatuto de Roma). ${ }^{55}$ Este principio ha sido aplicado igualmente en la orden de detención contra el presidente en ejercicio del Estado de Libia, Muamar Gaddafi por crímenes de lesa humanidad. ${ }^{56}$

En cuanto a los ministros, el ministro del Interior de Sudán ha sido igualmente objeto de una orden de detención por parte de la CPI, con imputaciones por crímenes de lesa humanidad y por crímenes de guerra constitutivos de homicidio intencional, ataques contra la población civil, destrucción de bienes de la población civil, violación, saqueo y

$54 \mathrm{CIJ}$, Affaire relative à des questions concernant l'obligation de poursuivre ou d'extrader (Belgique c. Sénégal), Ordonnance, CIJ Rôle général num. 144, párs. 2-5.

55 CPI, Pre-trial Chamber I (4 March 2009): The Prosecutor v. Omar Hassan Ahmad Al Bashir (“Omar Al Bashir"), ICC-02/05-01 / 09-1, Warrant of Arrest for Omar Hassan Ahmad Al Bashir; CPI, Pre-trial Chamber I (27 July 2010): The Prosecutor v. Omar Hassan Ahmad Al Bashir ("Omar Al Bashir”), ICC-02 / 05-01 / 09-95, Second Warrant of Arrest for Omar Hassan Ahmad Al Bashir (en adelante: “CPI, Al Bashir case, ICC-02/05-01/09-95”).

56 CPI, Pre-trial Chamber I (27 June 2011): The Prosecutor v. Muammar Mohammed Abu Minyar Gaddafi, Saif Al-Islam Gaddafi and Abdullah Al-Senussi, ICC-01/11-01/11-2, Warrant of Arrest for Muammar Mohammed Abu Minyar Gaddafi. 
atentados a la dignidad (artículos 8-2-c.i, 8-2-e-i, 8-2-e-xii, 8-2-e-vi, 8-2-e-v, 8-2-c-ii, respectivamente, del Estatuto de Roma). ${ }^{57}$ En su caso, el Ministro del Interior de Libia ha sido objeto de orden de detención por crímenes de lesa humanidad constitutivos de homicidio y persecución (artículo 7-1-a y 7-1-h del Estatuto de Roma). ${ }^{58}$

No obstante, este punto continúa siendo problemático, pues la responsabilidad internacional penal debe armonizarse con las inmunidades diplomáticas que están garantizadas por la costumbre internacional y por el derecho de los tratados, en particular por el artículo 41-2 delTratado de Viena del 18 de abril de 1961 sobre Relaciones Diplomáticas. ${ }^{59}$

En este sentido, a raíz de la orden de detención internacional proferida por el juez belga contra el ministro de Relaciones Exteriores de la República Democrática del Congo, AbdulayeYerodia Ndombasi, bajo cargos de crímenes de guerra y crímenes contra la humanidad, en 2002 la CIJ hizo un estudio de las legislaciones nacionales y de los estatutos de las jurisdicciones internacionales penales, para concluir que no se desprende una práctica de derecho consuetudinario que autorice la excepción a la regla que consagra la inmunidad de jurisdicción penal y la inviolabilidad de los ministros de Asuntos Exteriores en ejercicio, cuando éstos se encuentran imputados por crímenes de guerra y de lesa humanidad ante tribunales de terceros Estados:

La Cour en conclut que les fonctions d'un ministre des affaires étrangères sont telles que, pour toute la durée de sa charge, il bénéficie d'une immunité de juridiction pénale et d'une inviolabilité totales a l'étranger. Cette immunité et cette inviolabilité protègent l'intéressé contre tout acte d'autorité de la part d'un autre Etat qui ferait obstacle à l'exercice de ses fonctions. ${ }^{60}$

57 CPI, Pre-trial Chamber I (27 April 2007): The Prosecutor v. Ahmad Muhammad Harun (“Ahmad Harun") and Ali Muhammad Al Abd-al-Rahman ("Ali Kushayb”), ICC-02/05-01 / 07-2, Warrant of Arrest for Ahmad Harun.

58 CPI, Pre-trial Chamber I (27 June 2011): The Prosecutor v. Muammar Mohammed Abu Minyar Gaddafi, Saif Al-Islam Gaddafi and Abdullah Al-Senussi, ICC-01/11-01/11-3, Warrant of Arrest for Saif Al-Islam Gaddafi.

59 Tratado de Viena sobre Relaciones Diplomáticas (18 de abril de 1961).

60 CIJ, Mandat d'arrêt du 11 avril 2000 (République Démocratique du Congo c. Belgique), Arrêt, CIJ Recueil 2002, p. 3., párs. 53 y 54. 
Esta jurisprudencia llama la atención particularmente sobre la diferencia entre la competencia de terceros Estados y la competencia de los tribunales internacionales penales.

La CIJ ha establecido que la superioridad de la jurisdicción internacional permite que, con el tiempo y el cumplimiento pleno de las formalidades de Derecho Internacional, los individuos que gozan de inmunidades diplomáticas puedan ser llamados a responder por sus actos individuales ante la jurisdicción internacional penal. En contraste, la CIJ ha estimado que el contenido de las reglas sobre la responsabilidad internacional penal, incluido el artículo 7 del Estatuto de Núremberg y el artículo 27 del Estatuto de Roma, no permite constatar la existencia de un derecho consuetudinario en lo que se refiere a las jurisdicciones nacionales, y que las reglas que rigen la competencia de los tribunales nacionales deben distinguirse cuidadosamente de las reglas que rigen las inmunidades:

... la compétence n'implique pas l'absence d'immunité et l'absence d'immunité n'implique pas la compétence. C'est ainsi que, si diverses conventions internationales tendant à la prévention et à la répression de certains crimes graves ont mis à la charge des Etats des obligations de poursuite ou d'extradition, et leur ont fait par suite obligation d'étendre leur compétence juridictionnelle, cette extension de compétence ne porte en rien atteinte aux immunités résultant du droit international coutumier, et notamment aux immunités des ministres des affaires étrangères. Celles-ci demeurent opposables devant les tribunaux d'un Etat étranger, même lorsque ces tribunaux exercent une telle compétence sur la base de ces conventions. ${ }^{61}$

\section{La responsabilidad internacional penal no se extingue con el paso del tiempo}

La Convención sobre la Imprescriptibilidad de los Crímenes de Guerra y de Lesa Humanidad adoptada por la Asamblea General de las Naciones Unidas en $1968^{62}$ y la Convención Europea sobre la Imprescriptibilidad de los Crímenes contra la Humanidad y de los Crímenes de Guerra de

61 Ibidem, pár. 59.

6226 de noviembre de 1968. 
$1974^{63}$ disponen expresamente el principio de imprescriptibilidad de la responsabilidad penal por crímenes de guerra.

El mismo principio se encuentra reafirmado en el artículo 29 del Estatuto de Roma con respecto a los crímenes internacionales, que guarda silencio respecto a la prescripción de las penas, debido a que el Estatuto de Roma no prevé el juicio en ausencia del acusado (en rebeldía) (artículo 63-1 del Estatuto de Roma).

Aunque algunas jurisdicciones nacionales hayan establecido la prescripción de la acción penal en el derecho interno, conviene recordar que las Naciones Unidas han reiterado que:

Cuando así se disponga en un tratado aplicable o forme parte de otras obligaciones jurídicas internacionales, no prescribirán las violaciones manifiestas de las normas internacionales de derechos humanos ni las violaciones graves del derecho internacional humanitario que constituyan crímenes en virtud del derecho internacional. ${ }^{64}$

Esta afirmación es coherente con la jurisprudencia de la Corte Interamericana de Derechos Humanos (en adelante: Corte IDH), que ha sido enfática en reiterar la imprescriptibilidad de los delitos que tengan alguna relación con graves violaciones de los derechos humanos y del derecho internacional humanitario. La jurisprudencia interamericana es de obligatorio cumplimiento entre los Estados partes, y ha tenido efectos sobre numerosos sistemas jurídicos, en particular, frente a la atribución de la naturaleza de crímenes de lesa humanidad a los crímenes cometidos durante las dictaduras de América Latina:

La Corte resalta la importancia de que al decretar la prescripción de la acción penal por concierto para delinquir en casos de violaciones cometidas por miembros de grupos paramilitares, los funcionarios judiciales fundamenten su decisión

6325 de enero de 1974.

64 NU, doc. A/RES/60/147 (16-12-2005): Resolución aprobada por la Asamblea General [sobre la base del informe de la Tercera Comisión (A /60/509/Add.1)] Principios y directrices básicos sobre el derecho de las víctimas de violaciones manifiestas de las normas internacionales de derechos humanos y de violaciones graves del derecho internacional humanitario a interponer recursos y obtener reparaciones, 10 pp., pár. IV. 6. 
en una exhaustiva valoración probatoria para determinar que la pertenencia y participación en el grupo paramilitar, no tuvo relación con la comisión de graves violaciones de derechos humanos. ${ }^{65}$

8. La responsabilidad internacional penal no se extingue en los casos de cosa juzgada aparente o fraudulenta

La cosa juzgada es una consecuencia procesal del principio ne bis in idem que tiene una aplicación relativa para los crímenes internacionales bajo competencia de la CPI, incluidos los crímenes de guerra, en los casos de cosa juzgada aparente o fraudulenta.

El artículo 20-3 del Estatuto de Roma establece que el principio ne bis in idem no es aplicable cuando se busque sustraer al acusado de la competencia de la jurisdicción internacional penal, ni cuando no se haya instruido el proceso con imparcialidad e independencia, conforme a las garantías procesales reconocidas internacionalmente, o se haya instruido de modo incompatible con la intención de administrar justicia.

El artículo 8-4 del Pacto de San José incorpora el principio ne bis in idem, sin embargo, la jurisprudencia de la Corte IDH ha dejado establecido que este principio no es un derecho absoluto y no resulta aplicable cuando:

... la actuación del Tribunal que conoció el caso y decidió sobreseer o absolver al responsable de una violación a los derechos humanos o al derecho internacional obedeció al propósito de sustraer al acusado de su responsabilidad penal; ii) el procedimiento no fue instruido independiente o imparcialmente de conformidad con las debidas garantías procesales, o iii) no hubo la intención real de someter al responsable a la acción de la justicia. Una sentencia pronunciada en las circunstancias indicadas produce una cosa juzgada "aparente" o "fraudulenta" ... ${ }^{66}$

La Corte IDH ha afirmado igualmente que el hecho o la prueba sobreviviente puede habilitar una reapertura de investigación en el caso

65 Corte IDH, Caso de la Masacre de La Rochela v. Colombia, Sentencia de Fondo, Reparaciones y Costas del 11 de mayo de 2007, Serie C-163. pár. 291.

66 Corte IDH, Caso Almonacid Arellano y otros v. Chile, Sentencia de fondo del 26 de septiembre de 2006, Serie C-154, pár. 154. 
de graves violaciones a los derechos humanos y al derecho internacional humanitario, incluso si existe una sentencia absolutoria que ha hecho tránsito a cosa juzgada, puesto que las exigencias de la justicia, los derechos de las víctimas, y la letra y espíritu del Pacto de San José desplaza la protección del ne bis in idem. ${ }^{67}$

La jurisprudencia consolidada de la Corte IDH ha dejado constancia de la reprobación internacional de los juicios fraudulentos y del derecho a juzgar y sancionar los crímenes internacionales como excepción a la regla de la cosa juzgada:

El Derecho internacional de los derechos humanos en la hora actual, así como el Derecho penal internacional, reprueban la simulación de enjuiciamientos cuyo propósito o resultado se distancia de la justicia y pretende un objetivo contrario al fin para el que han sido dispuestos: injusticia, oculta entre los pliegues de un proceso "a modo", celebrado bajo el signo del prejuicio y comprometido con la impunidad o el atropello. De ahí que la justicia internacional sobre derechos humanos no se conforme necesariamente con la última decisión interna que analiza la violación de un derecho (y autoriza o permite que subsista la violación y persista el daño hecho a la víctima), y de ahí que la justicia penal internacional se rehúse a convalidar las decisiones de instancias penales domésticas que no pueden o no quieren hacer justicia. ${ }^{68}$

9. Las leyes de amnistía y de indulto no extinguen la responsabilidad internacional penal

Una parte de la doctrina internacional ha sostenido que en el estado actual del Derecho Internacional Penal no existe todavía una obligación general de los Estados de abstenerse de conceder amnistías e indultos por crímenes internacionales. Sin embargo, un tercer Estado o un tribunal internacional puede adelantar los procesos penales respectivos basándose en los tratados internacionales en vigor en la materia y ha-

67 Idem.

68 Corte IDH, Caso La Cantuta v. Perú, op. cit., voto razonado del juez García Ramírez, pár. 12. Véase igualmente: Corte IDH, Caso de la Masacre de La Rochela v. Colombia, cit., pár. 194, con reenvíos de jurisprudencia. 
ciendo caso omiso de las amnistías e indultos otorgados, sin que por ello esté atentando contra el principio del respeto a la soberanía de los Estados:

There is not yet any general obligation for States to refrain from enacting amnesty laws on these crimes. Consequently, if a State passes any such law, it does not breach a customary rule. Nonetheless if a court of another State having in custody persons accused of international crimes decide to prosecute them although in their national State they would benefit from an amnesty law, such court would not thereby act contrary to general international law, in particular to the principle of respect for the sovereignty of other States. ${ }^{69}$

Otra parte de la doctrina sostiene que, sin lugar a dudas, las amnistías y los indultos quedaron proscritos en materia de crímenes internacionales y para los Estados pesa una obligación general en la materia:

... Estas amnistías o indultos no producen el menor efecto jurídico ni para los tribunales penales internacionales o internacionalizados, ni para los tribunales internos distintos a los del Estado que concedió la amnistía o el indulto. Incluso por contradecir normas imperativas del Derecho Internacional general, tampoco son válidas ni siquiera para los tribunales internos del Estado que las dictó. ${ }^{70}$

En la práctica de los Estados, después de la Segunda Guerra Mundial las leyes de amnistía e indulto han venido excluyendo progresivamente los crímenes de derecho internacional, en el entendido que estas leyes puedan derivar en cosa juzgada aparente con el propósito de sustraer a los perpetradores de crímenes internacionales de su responsabilidad penal. ${ }^{71}$

En el asunto contra Anto Furundzija, comandante de la policía local bosnia de la provincia de Nadioci, acusado de violación y tortura de

69 Cassese, Antonio, International Criminal Law, cit., p. 315.

70 Bou Franch, Valentín y Fernández de Casadevante Romaní, Carlos, La inclusión del terrorismo entre los crímenes internacionales previstos en el Estatuto de la Corte Penal Internacional, Burriana, MINIM agencia ediciones, 2009, p. 109.

$71 \mathrm{CDH}$, doc. HR/PUB/09/1 (2009): Instrumentos del Estado de derecho para sociedades que han salido de un conflicto. Amnistías, p. 7. 
mujeres musulmanas de ascendencia croata, el TPIY ha ratificado que las leyes de amnistía e indulto aplicadas a casos de tortura nacen viciadas de nulidad absoluta, debido a que contravienen obligaciones de jus cogens, relativas a la persecución y sanción de crímenes internacionales. ${ }^{72}$ ElTPIY ha confirmado dos tipos de consecuencias derivadas de la prohibición jus cogens de los crímenes internacionales: (1) en el plano interestatal, el hecho de que cualquier norma interna que autorice o perdone la tortura es nula de pleno derecho a nivel internacional, y (2) el plano individual, el hecho de que todos los Estados tengan la obligación de perseguir y sancionar o extraditar a los individuos responsables de tales crímenes. ${ }^{73}$

El Tribunal Especial de Sierra Leona (tribunal híbrido) se ha pronunciado en el mismo sentido, indicando que las amnistías e indultos en materia de crímenes internacionales son violatorias de obligaciones internacionales de jus cogens que pesan sobre los Estados:

... given the existence of a treaty obligation to prosecute or extradite an offender, the grant of amnesty in respect of such crimes as are specified in Articles 2 to 4 of the Statute of the Court is not only incompatible with, but is in breach of an obligation of a State towards the international community as a whole. Nothing in the submissions made by the Defence and the interveners detracts from that conclusion... ${ }^{74}$

De hecho, cuando una ley de amnistía o indulto es considerada ilícita por una instancia competente, todas las leyes o decretos reglamentarios que hayan tenido por propósito impedir los juicios contra los mismos crímenes pierden cualquier efecto jurídico. En esta línea de análisis, la Corte IDH ha considerado inadmisibles las amnistías, indultos y leyes tendientes a evitar el enjuiciamiento por crímenes consistentes en graves violaciones al derecho internacional de los derechos humanos por ser incompatibles con los compromisos convencionales de los Estados Partes:

72 TPIY, Trial Furundzija, IT-95-17/1-T, op. cit., párs. 154 y 155.

73 Ibidem, párs. 155 y 156.

74 TESL, Appeals Chamber (13 March 2004): The Prosecutor v. Morris Kallon, Case No. SCSL-2004-15-AR72(E), and The Prosecutor v. Brima Bazzy Kamara, Case No. SCSL-2004-16AR72(E), Decision on Challenge to jurisdiction: Lomé accord amnesty, pár. 73. 
... son inadmisibles las disposiciones de amnistía, las disposiciones de prescripción y el establecimiento de excluyentes de responsabilidad que pretendan impedir la investigación y sanción de los responsables de las violaciones graves de los derechos humanos tales como la tortura, las ejecuciones sumarias, extralegales o arbitrarias y las desapariciones forzadas, todas ellas prohibidas por contravenir derechos inderogables reconocidos por el Derecho Internacional de los Derechos Humanos... ${ }^{75}$

Como parte del respeto a los compromisos convencionales, la jurisprudencia internacional ha venido sosteniendo que cuando las leyes de amnistía e indulto obstaculizan el cumplimiento de estos compromisos, suscritos por los Estados en materia de persecución y sanción de graves crímenes, ellas son en sí mismas violatorias de los tratados suscritos y no son oponibles en derecho internacional. ${ }^{76}$

Así, el conjunto de principios aplicables en derecho internacional penal a la responsabilidad de los individuos se erige como la premisa fundamental de la atribución de la responsabilidad, a títulos diferentes de responsabilidad principal y accesoria y según las teorías de atribución desarrolladas por los diferentes tribunales internacionales.

\section{Conclusiones}

La práctica internacional reciente en materia de principios de la responsabilidad penal continúa siendo materia de debate en algunos sectores de la doctrina. Temas como la validez de las leyes de amnistía e indulto o el alcance de las inmunidades diplomáticas en el marco de acusaciones por crímenes internacionales ocupan un lugar central. Sin embargo, la jurisprudencia se ha venido unificando a partir del estudio de crímenes de genocidio, crímenes de guerra y crímenes contra la humanidad, ocurridos en los territorios de la antigua Yugoslavia, Ruanda y otros países

75 Corte IDH. Caso Barrios Altos v. Perú, Sentencia de Fondo del 14 de marzo de 2001, Serie C-75, pár. 41.

76 Ibidem, pár. 43. 
bajo estudio de la CPI, como la República Democrática del Congo, la República Centroafricana y Sudán.

Es importante recordar que el Estatuto de Roma debe ser interpretado en el marco estricto del derecho de los tratados, con lo cual la actividad de la CPI se mantiene, a diferencia de los tribunales ad hoc, estrechamente ligada a la Convención de Viena de 1969 y sus disposiciones concordantes.

En este sentido, aunque este artículo se centra en los desarrollos de la jurisprudencia aplicable al Estatuto de Roma, resulta necesario señalar que los alcances de los principios de la responsabilidad penal por crímenes internacionales van más allá de la jurisdicción de la CPI, y se aplican caso por caso y con algunas adaptaciones a las legislaciones internas y a los mandatos de los tribunales híbridos, como se ha señalado en la jurisprudencia del Tribunal Especial para Sierra Leona y como se viene constatando en la jurisprudencia reciente de países como Colombia.

En todos los casos, la jurisprudencia consolidada de los tribunales ad hoc y de la CPI ha hecho uso de los principios generales de derecho internacional, del derecho consuetudinario en materia de principios elementales de humanidad y conducción de hostilidades así como de otros grandes principios de derechos humanos y derecho internacional de los conflictos armados a la hora de establecer los principios aplicables en materia de responsabilidad internacional penal. Como resultado, esta lista de principios aplicables a la responsabilidad internacional penal no tiene un valor exhaustivo pero constituye la base del equilibrio, necesaria entre el deber de administrar justicia y los derechos de los individuos acusados de graves crímenes.

La jurisprudencia consolidada en la materia se refiere a casos con umbrales altos de gravedad, constata la existencia de estructuras organizadas de control detrás de los crímenes perpetrados y no excluye un estudio posterior y necesario, de la responsabilidad internacional de los Estados, más allá de la responsabilidad penal de los individuos. Este último es un tema amplio y actual que merece ser estudiado y que se encuentra sujeto a la evolución de los estudios de la CDI por sus consecuencias en materia de soberanía estatal.

Los desarrollos futuros de la jurisprudencia internacional penal permitirán mayores precisiones en materia de principios que rigen la res- 
ponsabilidad penal de los individuos en el plano internacional. Por el momento, la pertinencia de las conclusiones de la jurisprudencia de la CPI en cuanto a la interpretación del Estatuto de Roma se halla probada y confirmada por el mandato del artículo 21 del propio Estatuto, lo cual no excluye profundas discusiones en el seno de la Corte acerca de los límites de la imputación del hecho propio, con miras a consolidar una teoría unificada de la responsabilidad internacional penal.

\section{DOCUMENTACIÓN}

\section{Instrumentos internacionales}

Convención Americana sobre Derechos Humanos, suscrita en la Conferencia especializada Interamericana sobre Derechos Humanos de San José de Costa Rica (22 de noviembre de 1969).

Convención Europea sobre la Imprescriptibilidad de los Crímenes contra la Humanidad y de los Crímenes de Guerra adoptada por el Consejo de Europa (25 de enero de 1974).

Convención sobre la imprescriptibilidad de los crímenes de guerra y de los crímenes de lesa humanidad (26 de noviembre de 1968)

Estatuto de la Corte Penal Internacional, Conferencia Diplomática de Plenipotenciarios de las Naciones Unidas sobre el establecimiento de una Corte Penal Internacional (17 de julios de 1998).

Estatuto del Tribunal de Núremberg anexo al Acuerdo para el establecimiento de un Tribunal Militar Internacional encargado del juicio y castigo de los principales criminales de guerra del Eje europeo, Londres (8 de agosto de 1945).

Tratado de Viena sobre Relaciones Diplomáticas (18 de abril de 1961).

\section{Documentos oficiales}

CDH, doc. HR/PUB/09/1 (2009): Instrumentos del Estado de derecho para sociedades que han salido de un conflicto. Amnistías, $52 \mathrm{pp}$. 
CDI, doc. A/31/10* (23-7-1976): Informe de la Comisión de Derecho Internacional sobre la labor realizada en su 280 . período de sesiones, $165 \mathrm{pp}$. CDI, doc. A/39/10* (27-7-1984): Informe de la Comisión de Derecho Internacional sobre la labor realizada en su 36o. período de sesiones, $113 \mathrm{pp}$. CDI, doc. A/56/10 (10-8-2001): Texto del proyecto de artículos sobre la responsabilidad del Estado por hechos internacionalmente ilícitos con sus comentarios, $591 \mathrm{pp}$.

ILC, doc. A/CN.4/34 (29-7-1950): Report of the International Law Commission on the work of its Second Session, $385 \mathrm{pp}$.

Ley Orgánica 10/1995, del 23 de noviembre, del Código Penal, Reino de España, BOE núm. 0281, del 24 de noviembre de 1995.

Loi 92-683 du 22 juillet 1992, portant réforme des dispositions générales du code pénal de la Republique de France, version consolidée au 7 janvier 2011.

NU, doc. A/50/22 Suplemento 22 (6-9-1995): Informe del Comité Especial sobre el establecimiento de una Corte Penal Internacional, $66 \mathrm{pp}$.

NU, doc. A/CONF/183/C.1/WGGP/L.5 (19-6-1998): Working paper on article 23, paragraphs 5 and 6, $2 \mathrm{pp}$.

NU, doc. A/RES/60/147 (16-12-2005): Resolución aprobada por la Asamblea General [sobre la base del informe de la Tercera Comisión (A /60/509/ Add.1)] Principios y directrices básicos sobre el derecho de las víctimas de violaciones manifiestas de las normas internacionales de derechos humanos y de violaciones graves del derecho internacional humanitario a interponer recursos y obtener reparaciones, $10 \mathrm{pp}$.

NU, doc. A/RES/95(I) (11-12-1946): Confirmación de los principios de Derecho Internacional reconocidos por el estatuto del Tribunal de Núremberg, $1 \mathrm{p}$.

\section{Jurisprudencia}

CIJ, Affaire de la Barcelona Traction, light and power Company, limited (nouvelle requête: 1962), (Belgique c. Espagne), Deuxième phase, Arrêt du 5 février 1970, ICJ Recueil 1970.

CIJ, Affaire relative à des questions concernant l'obligation de poursuivre ou d'extrader (Belgique c. Sénégal), Ordonnance, CIJ Rôle général num. 144. 
CIJ, Certaines questions concernant l'entraide judiciaire en matière pénale (Djibouti c. France), Arrêt du 4 juin 2008, CIJ Recueil 2008, p. 177. CIJ, Mandat d'arrêt du 11 avril 2000 (République Démocratique du Congo c. Belgique), Arrêt, CIJ Recueil 2002.

CIJ, Military and Paramilitary Activities in and against Nicaragua (Nicaragua vs. United States of America), Merits, Judgment of June 27th 1986, ICJ Reports 1986.

CIJ, The Corfou Channel case (United Kingdom vs. Albania), Judgment of April 9th 1949, ICJ Reports 1949.

Corte IDH, Caso Almonacid Arellano y otros v. Chile, Sentencia de fondo del 26 de septiembre de 2006, Serie C-154.

Corte IDH, Caso de la Masacre de La Rochela v. Colombia, Sentencia de Fondo, Reparaciones y Costas del 11 de mayo de 2007, Serie C-163. Corte IDH, Caso La Cantuta v. Perú, Sentencia de Fondo, Reparaciones y Costas del 29 de noviembre de 2006, Serie C-162.

Corte IDH. Caso Barrios Altos v. Perú, Sentencia de Fondo del 14 de marzo de 2001, Serie C-75, pár. 41.

CPI, Chambre préliminaire I (29 janvier 2007): Le Procureur c. Thomas Lubanga Dyilo, ICC-1/04-1/06-803, Décision sur la confirmation des charges.

CPI, Chambre Préliminaire III (23 mai 2008): Le Procureur c. Jean-Pierre Bemba Gombo, ICC-01/04-01/08-1, Mandat d'arrêt à l'encontre de Jean-Pierre Bemba Gombo.

CPI, Pre-trial Chamber I (27 April 2007): The Prosecutor v. Ahmad Muhammad Harun ("Ahmad Harun") and Ali Muhammad Al Abd-al-Rahman (“Ali Kushayb”), ICC-02/05-01/07-2, Warrant of Arrest for Ahmad Harun.

CPI, Pre-trial Chamber I (27 July 2010): The Prosecutor v. Omar Hassan Ahmad Al Bashir ("Omar Al Bashir"), ICC-02/05-01/09-95, Second Warrant of Arrest for Omar Hassan Ahmad Al Bashir.

CPI, Pre-trial Chamber I (27 June 2011): The Prosecutor v. Muammar Mohammed Abu Minyar Gaddafi, Saif Al-Islam Gaddafi and Abdullah AlSenussi, ICC-01/11-01/11-2, Warrant of Arrest for Muammar Mohammed Abu Minyar Gaddafi.

CPI, Pre-trial Chamber I (27 June 2011): The Prosecutor v. Muammar Mohammed Abu Minyar Gaddafi, Saif Al-Islam Gaddafi and Abdullah Al-Senussi, ICC-01/11-01/11-3, Warrant of Arrest for Saif Al-Islam Gaddafi. 
CPI, Pre-trial Chamber I (30 September 2008): The Prosecutor v. Germain Katanga and Mathieu Ngudjolo Chui, Case ICC-1/04-1/07-717, Decision on the confirmation of charges.

CPI, Pre-trial Chamber I (4 March 2009): The Prosecutor v. Omar Hassan Ahmad Al Bashir ("Omar Al Bashir"), ICC-02/05-01/09-1, Warrant of Arrest for Omar Hassan Ahmad Al Bashir.

CPI, Pre-trial Chamber II (15 June 2009): The Prosecutor v. Jean-Pierre Bemba Gombo, ICC-1/05-1/08-424, Decision Pursuant to Article 61(7)(a) and (b) of the Rome Statute on the Charges of the Prosecutor Against Jean-Pierre Bemba Gombo.

TESL, Appeals Chamber (13 March 2004): The Prosecutor v. Morris Kallon, Case No. SCSL-2004-15-AR72(E), and The Prosecutor v. Brima Bazzy Kamara, Case No. SCSL-2004-16-AR72(E), Decision on Challenge to jurisdiction: Lomé accord amnesty.

TMIN, Opinion and Judgment of the International Military Tribunal for the Trial of German Major War Criminals, Núremberg, 1946.

TMIN, Trial of the Major War Criminals before the International Military Tribunal, vol. I, Núremberg, 1947.

TMIN, Trial of the Major War Criminals before the International Military Tribunal, vol. II, Núremberg, 1948.

TPIR, Chambre d'Appel (1 juin 2001): Le Procureur c. Jean-Paul Akayesu, ICTR-96-4-A, Arrêt.

TPIR, Trial Chamber I (2 September 1998): The Prosecutor v. Jean-Paul Akayesu, Case ICTR-96-4-T, Judgment.

TPIR, Trial Chamber I (27 January 2000): The Prosecutor v. Alfred Musema-Uwimana, Case ICTR-96-13-T, Judgment and Sentence.

TPIY, Appeals Chamber (15 July 1999): The Prosecutor v. Dusko Tadic "Dule", Case IT-94-1-A, Judgment.

TPIY, Appeals Chamber (24 March 2000): The Prosecutor v. Zlatko Aleksovski, Case IT-95-14-A, Judgment.

TPIY, Chambre d'Appel (2 October 1995): Le Procureur c. Dusko Tadic alias Dule, Affaire IT-94-1, Arrêt relatif à l'appel de la Défense concernant l'exception préjudicielle d'incompétence.

TPIY, Trial Chamber II (10 December 1998): The Prosecutor v. Anto Furundzija, Case IT-95-17/1-T, Judgment. 
Ambos, Kai, “Article 25: Individual Criminal Responsability”, en Triffterer, Otto (ed.), Commentary on the Rome Statute of the International Criminal Court, Observer's notes Article by Article, 2a. ed., Múnich, C. H. Beck, Hart, Nomos, 2008.

Bergsmo, Morten y Triffterer, Otto, "Preamble", en TriffTerer, Otto (ed.), Commentary on the Rome Statute of the International Criminal Court, Observer's notes Article by Article, 2a. ed., Múnich, C. H. Beck, Hart, Nomos, 2008.

Bou Franch, Valentín y Fernández de Casadevante Romaní, Carlos, La inclusión del terrorismo entre los crímenes internacionales previstos en el Estatuto de la Corte Penal Internacional, Burriana, MINIM agencia ediciones, 2009.

Bouloc, Bernard, Droit pénal général, 21a. ed., París, Dalloz, 2009, Colección Précis.

CASSESE, Antonio, International Criminal Law, 2a. ed., Nueva York, Oxford University Press, 2008.

DAVID, Eric, Principes de droit des conflits armés, 4a. ed., Bruselas, Bruylant, 2008.

DesPortes, Frédéric y LE GuneHEC, Francis, Droit pénal général, 15a. ed., París, Economica, 2008.

SuDRE, Frédéric, Droit européen et international des droits de l'homme, 8a. ed., París, Presses Universitaires de France, 2009.

Werle, Gerhard, Principles of the International criminal law, 2a. ed., La Haya, TMC Asser Press, 2009.

Williams, Sharon A. y Schabas, William A., "Article 13: Exercise of Jurisdiction", en TriffTERER, Otto (ed.), Commentary on the Rome Statute of the International Criminal Court, Observer's notes Article by Article, 2a. ed., Múnich, C. H. Beck, Hart, Nomos, 2008.

Zugaldía Espinar, José Miguel (dir.), Fundamentos de derecho penal. Parte general, 4a. ed., Valencia, Tirant lo Blanch, 2010. 